\title{
Surface Integrity Characterization of Hardened AISI 4340 Steel in Grinding Process with Biodegradable Formulations of Cutting Fluids
}

\author{
Cintia Braga ${ }^{a}$, Leonardo Roberto da Silva ${ }^{a *}$, Evanilton José Alves Barbosa ${ }^{a}$,
}

Elaine Carballo Siqueira Corrêa ${ }^{a}$

\author{
${ }^{a}$ Materials Engineering Department, Federal Center of Technological Education of Minas Gerais, Av. \\ Amazonas, 5253, Belo Horizonte, MG, Brazil
}

Received: September 12, 2016; Revised: December 19, 2016; Accepted: January 25, 2017

\begin{abstract}
Surface integrity has significant effect on service performance of a component. The surface integrity of workpieces submitted to grinding process depends on the conditions of cooling produced by cutting fluids, which are used to avoid microstructural damage in the process. However, cutting fluids are harmful to the environment and human health, and appear as a crucial element to the optimization of the manufacturing process. In this scenario, biodegradable cutting fluids, such as formulations based on vegetable oils, appear as promising possibility to a cleaner production in grinding process. This study analyzed the surface integrity of AISI 4340 steel, quenched and tempered, in the external cylindrical plunge grinding process with the use of six different formulations of biodegradable cutting fluids (with oils of soybeans, corn, and mineral oil, pure and with additives). The performance of the application of cutting fluids was evaluated by characterizing the microstructure by Scanning Electron Microscopy - SEM and microhardness and roughness measurements. The results showed that the surface integrity of the components was not significantly damaged, which proves the efficiency of biodegradable cutting fluids and feasibility of its use in grinding process.
\end{abstract}

Keywords: Grinding, Surface integrity, Biodegradability, Materials characterization, Roughness, Clean production, Vegetable oil

\section{Introduction}

Lubricants are widely used in all sectors of industry for cooling and lubricating the tool and work-piece interface in order to enhance machinability, as well as flushing the debris originated on the abrasive process ${ }^{1,2}$. Despite the great importance of the use of cutting fluids in machining processes, this use also brings serious disadvantages, such as ecological and environmental problems, leading research works in the last decades to reduce the use of synthetic lubricants ${ }^{2,3}$. Recently, biodegradable lubricants have been gradually replacing the synthetic ones. Biodegradable cutting fluids that accomplish the lowest amount of environmental contamination can provide high reliability and satisfactory economic conditions. Additionally, the output of bio-based cutting fluids is cleaner and contributes less mist in the air, subsequently minimizing the occupational health risks ${ }^{1}$. Although bio-based (vegetation) cutting fluids are not perfect in all aspects, they have the least negative impact on the environment compared to other cutting fluids ${ }^{4}$.

Conventional cutting fluids, which have low prices, suffer from several remarkable disadvantages that restrict their applications in machining processes. Using these fluids for several times can usually induce chemical changes in their properties, even microbial toxins can be generated by bacteria and fungi present in such fluids, especially in water-soluble

* e-mail: lrsilva@deii.cefetmg.br cutting fluids ${ }^{5,6}$. On the other hand, using a cutting fluid for several times can lead to the oil and chip contamination, and therefore, this contamination in combination with the chemical changes can reduce the performance of the cutting fluid and may have adverse impacts on the environment ${ }^{5}$.

Machining industries concern for development of preventive legislation and the increased interest in almost green products reduce the soil pollution by biodegradability which make the manufacturing processes a clean process. Vegetable oil-based cutting fluids seem to be the best alternatives to mineral oil-based cutting fluids due to certain inherent chemical properties and their biodegradability ability. Biodegradability is the main aspect with respect to environmentally friendly. Biodegradable substance is susceptible to biochemical breakdown by the action of micro-organism?

Grinding is one of the most important machining processes once it allows achieving high processing quality and surface integrity, which motivates its application in the production of parts with strict dimensional tolerance and low roughness ${ }^{8,9}$.

Grinding employs a higher unit grinding force and grinding speed than other cutting processes and therefore involves a significantly higher grinding energy. Most of this energy is converted into thermal energy. This thermal energy has different distribution patterns from other cuttings. Most grinding heat (approximately $80 \%$ ) is transferred into the workpiece ${ }^{10}$. 
The grinding process involves the contact of the workpiece surface and the irregular abrasive grains scattered on the grinding wheel ${ }^{8,11,12}$. This interaction, in addition with the high grinding speeds involved, causes temperature rise at the workpiece/wheel interface, which may compromise the surface microstructure of the components. If the temperature values exceed acceptable levels, thermal damage ad residual stress may occur, thus compromising the ground surface and sub-surface integrity by cracking, microstructural alterations, generating dimensional inaccuracy, in addition to rapid oxidation and corrosion ${ }^{13,14}$. High temperatures in the grinding process also has significant influences on the grinding property of abrasive grits, which may directly decrease the service life of the grinding whee $1^{4,9,12}$.

Many works reports a relation between the surface integrity of machined components and their functional performance, regarding tribological properties, fatigue strength and stress corrosion cracking resistance ${ }^{4,15,16}$, justifying the importance of improving the different cooling technologies applied in grinding process to reduce thermal damage and the problems that affect the surface quality of components. The gathered heat leads to high temperature, and without the lubrication and cooling effect of the grinding fluid, the grinding wheel wears seriously, and the workpiece precision and surface integrity deteriorate ${ }^{17}$.

Mineral oil based cutting fluids is the most common type of lubricant used in metalworking industry. Although, this enormous use of petroleum based oils is undesirable due to its toxicity and negative health and environment impact they cause $^{18,19,20,21,22}$. There is a global trend to reduce the use of such oils, using as an alternative the environmentally friendly cutting fluids, such as oils of vegetable origin. Recently many researchers have focused their work on the use of cutting fluids of biodegradable origin in various machining processes, reporting promising results ${ }^{18,19,21}$. However, few works deals with the use of pure and low-cost vegetable oils, such as soybean and corn oils, in severe machining processes, such as grinding. The majority of researches involve the use of cutting fluid formulations containing biodegradable oils added to a mineral based cutting fluid. In this context, the purpose of this study is the microstructural characterization of the surface of specimens of AISI 4340 hardened steel, submitted to grinding process with different formulations of biodegradable cutting fluid, including the use of pure vegetable oils, evaluating surface integrity of components. AISI 4340 steel is widely used in industry, especially for applications of machine part-members. This steel combines excellent levels of strength and toughness, besides the ability to vary mechanical properties by heat treatment ${ }^{23,24}$, which turns this steel a good candidate for surface integrity and microstructural changes evaluation after its submission to the thermal cycle of the grinding process. The evaluation consisted of roughness measurements, microstructural analysis in a Scanning Electron Microscope (SEM) and microhardness profile measurements to complement the results observed in the micrographs.

\section{Materials and Methods}

For the tests performed in this study, cylindrical specimens of AISI 4340 steel quenched and tempered, with an average hardness of $52 \mathrm{HRc}$ have been made. The pre-defined dimensions were $37 \mathrm{~mm}$ diameter and $42 \mathrm{~mm}$ long machined.

The tests were performed in a universal cylindrical grinding (TosHostivar, 9kW), and conventional grinding wheel of aluminum oxide $\left(\mathrm{Al}_{2} \mathrm{O}_{3}-\varnothing 350\right.$ x Ø127 x $50.8 \mathrm{~mm}$ - FE 38A60KV). The machining conditions were chosen to simulate the real conditions of a grinding operation. Table 1 shows the parameter specifications.

Table 1. Machining condition specifications.

\begin{tabular}{cc}
\hline Parameters & Condition \\
\hline Plunge speed & $1.2 \mathrm{~mm} / \mathrm{min}$ \\
Spark out & 5 seconds \\
Number of cycles & 36 \\
Cycle time & 10 seconds \\
Allowance for grinding & $0.2 \mathrm{~mm}$ at the end of each cycle
\end{tabular}

At the end of the grinding it was possible to obtain a reduction of $7.2 \mathrm{~mm}$ in diameter of the specimens.

The cutting fluids used in grinding were: mineral oil Mecafluid 14SC Petronas, paraffinic base, containing additives suitable for general cutting operations; and vegetable oils of soybeans and corn, purchased in Brazilian market.

To create the formulations were used: extreme pressure additive Liovac 580, cooling agent Liovac PLO, and antioxidant Naugalube 438-L. Table 2 presents the formulations of cutting fluid used in the tests.

Three specimens were grinded for each formulation of cutting fluid shown in Table 1, totaling 21 pieces machined by the end of the tests.

The roughness was defined by the amplitude parameter Ra, according to JIS B $0601-2001^{25}$; cut-off of $0.8 \mathrm{~mm}$ was used. The measurements were made with a roughness tester Mitutoyo, model SJ-301. The roughness was measured at four radial positions equidistant to $90^{\circ}$ approximately. Subsequently the average and standard deviation of the results were calculated.

To characterize the microstructure of the surface of the grinded parts and check for possible damage in the surface caused by thermal and mechanical stresses occurring for each condition of cooling investigated, a microstructural analysis was performed using scanning electron microscopy.

The specimens that showed the roughness value closest to the average in each condition of cooling were chosen for microstructural analysis, beyond the sample without grinding, totaling eight samples analyzed. The samples were removed through a cut in the cross section of the test specimen and subsequently embedded in acrylic autopolymerizing so that the cross section was exposed for grinding. After embedding, the samples were abraded with sandpapers of different particle sizes $(220,320,400$ to 600 mesh) and polished on a polishing machine with diamond slurry for metallographic polishing with 
Table 2. Cutting fluid formulations.

\begin{tabular}{cc}
\hline & Formulations \\
\hline Designation & Additive Concentration (\%v.v-1) \\
Mineral $100 \%$ & - \\
Soybean $100 \%$ & - \\
Corn $100 \%$ & $5 \%$ Liovac 580/ 1\% Liovac PLO/ 1\% Naugalube 438-L/ Soybean oil \\
Soybean 5 & $5 \%$ Liovac 580/ 1\% Liovac PLO/ 1\% Naugalube 438-L/ Corn oil \\
Corn 5 & Soybean $5(50 \%+$ Mineral oil $50 \%)$ \\
Mix 1 & Corn $5(50 \%+$ Mineral oil $50 \%)$ \\
Mix 2 &
\end{tabular}

particle size of $3 \mu \mathrm{m}$ and $9 \mu \mathrm{m}$. All samples were chemically attacked using 3\% Nital. The scanning electron microscope used was 550 SSX Superscan - Shimadzu, where 1000x magnifications were performed.

In order to complement the microstructural evaluation of the parts surface, Vickers microindentation hardness measurements were taken to obtain the microhardness profile of the samples. The measurements were carried out using a Vickers microindentation hardness tester Shimadzu model HMV2 following the ASTM E-384-9926. Samples evaluated in microindentation hardness tests were taken from the same specimens evaluated in the SEM. Metallographic preparation consisted of grinding on sandpaper particle size from 400 to 600 mesh and subsequently polishing with diamond slurry for polishing metallographic with particle sizes of $3 \mu \mathrm{m}$ to 9 $\mu \mathrm{m}$. After polishing the surface of the samples had a plane with a length between $3.5 \mathrm{~mm}$ and $4.5 \mathrm{~mm}$.

The load applied in each test was $300 \mathrm{gf}$ for a period of $15 \mathrm{sec}$. During the tests 10 measurements were taken in two different regions of the samples, to obtain microhardness values at different depths in sub-surface part. The first line of indentation was made with a distance of $3.0 \mathrm{~mm}$ from one end of the sample and the second with the same distance from the other end. The ten indentations in each row were made at a distance of $0.1 \mathrm{~mm}$ between one indentation and another, and $0.1 \mathrm{~mm}$ over the edge of the polishing plane created, as shown in the diagram of Figure 1 (a). Measurements of the same piece but not passed through metallographic preparation were also made, for the value of hardness at a depth 0 , at the surface. Figure 1 (b) shows the side view of the plan made in polishing and geometric relations to calculate the depth of indentation.

In figure 1 (b), P represents the depth and D is the distance between the indentation and the edge of the plane. By the Pythagorean Theorem, there are the equations 1 and 2:

$$
\begin{gathered}
\alpha^{2}=\mathrm{R}^{2}-\left(\frac{L}{2}\right)^{2} \\
\chi^{2}=\alpha^{2}+\left(\frac{\mathrm{L}}{2}-d\right)^{2}
\end{gathered}
$$

By observing figure 2, there is the equation 3:

$$
\mathrm{p}=R-\chi
$$

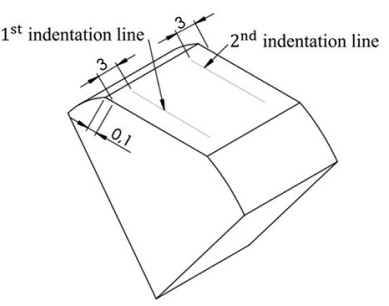

(a)

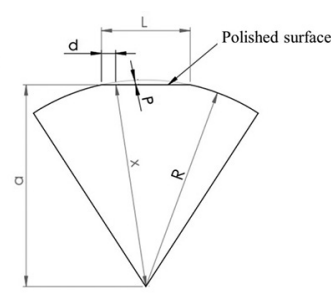

(b)
Figure 1. Microhardness profile measurement: indentation lines (a) and geometric relations to calculate the depth of indentation (b).

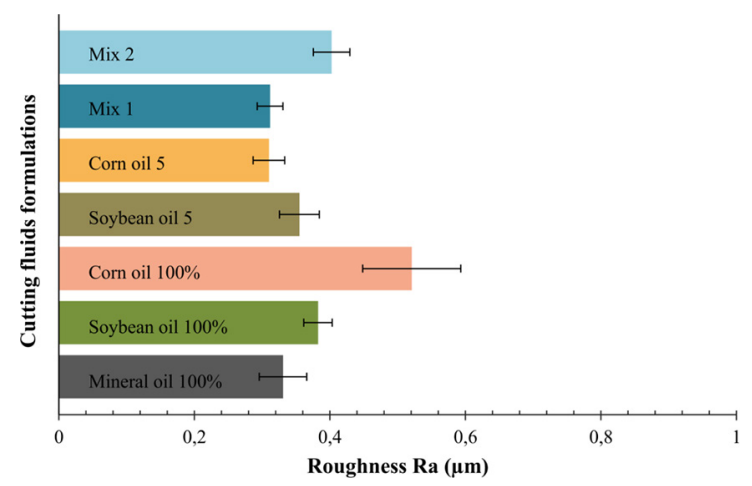

Figure 2. Roughness values of the specimens grinded in different conditions of cooling.

Using equations 1, 2 and 3 , and standardizing the value of the radius as $15 \mathrm{~mm}$ and the plane created with a length of $4 \mathrm{~mm}$, was possible to calculate the depth (distance from the original surface) where each measurement was performed. The value of the depth measurements ranged from $13.0 \mu \mathrm{m}$ to $100.3 \mu \mathrm{m}$.

\section{Results and Discussion}

The average values of roughness, assessed by Ra parameter are shown in Figure 2.

It is noticed that the roughness values found in the specimens machined with different conditions of cooling were similar, with the exception of grinding with $100 \%$ corn oil and Mix 2, which showed higher values of roughness. Roughness values of all tested samples, although, are 
within the acceptable range, since Ra parameter in grinding processes is between 0.2 and $1.6 \mu \mathrm{m}^{25}$. Cutting fluids which provided parts with a lower roughness were Mix 1 and Corn oil 5, which shows the best efficiency of corn oil with additives when compared to the mixture of such oil with mineral cutting fluid, although the behavior observed for soybean oil is the opposite: the cutting fluid performance was better with soybean oil blended with mineral oil than soybean oil with additives only. The similarity between the surface roughness of the grinded samples with some of biodegradable formulations and the surface roughness of the samples grinded with mineral oil reveals the potential of vegetal-based cutting fluids as substitutes for mineral-based oils. These observations are in line with the results obtained by Wang et $a l^{17}$, where it was found that grinding operations with vegetable oils promote good surface quality, which is directly related to the roughness of the component ${ }^{17}$.

Figures 3-6 shows the microstructures of the samples analyzed by SEM in order to investigate possible microstructural changes resulting from damage to the material sub-surface due to thermal and mechanical stresses inherent to grinding process.

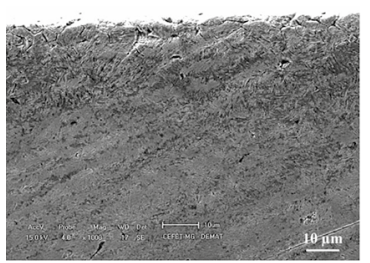

(a)

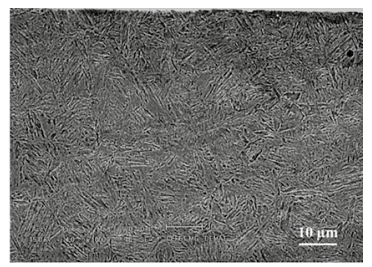

(b)
Figure 3. Micrographs of the not grinded sample (A) and grinded with Mineral Oil (B).

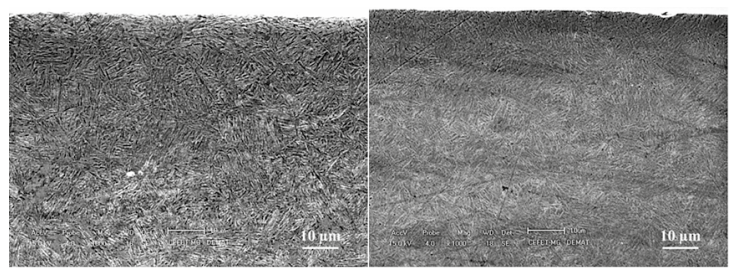

(a)

(b)

Figure 4. Micrographs of samples grinded with Soybean pure (A) and Soybean 5 (B).

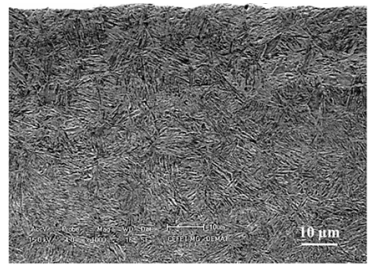

(a)

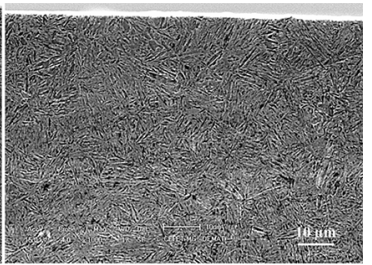

(b)
Figure 5. Micrographs of samples grinded with Corn pure (A) and Corn 5 (B).

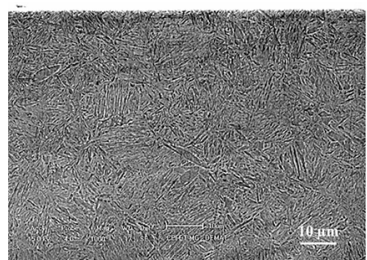

(a)

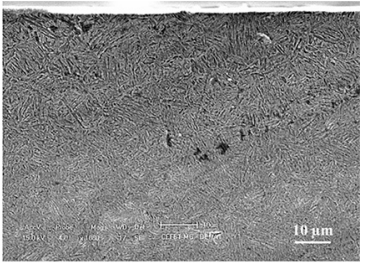

(b)
Figure 6. Micrographs of samples grinded with Mix 1 (A) and Mix 2 (B).

It is observed presence of martensite dispersed on the surface of all grinded samples. The sample which was not submitted to grinding, besides presenting some superficial cracks, showed a martensitic microstructure less acicular and more diffuse than the others. All used formulations of cutting fluids behaved effectively, since the changes in microstructure (martensite formation on the surface) are expected in the grinding process and does not lead to damage the surface integrity of the pieces. The micrograph of the sample whose appearance more resembles the appearance of the micrograph of the sample grinded with mineral oil was the one grinded with Mix 1 cutting fluid formulation. A martensitic microstructure more acicular can be associated with a higher tetragonality of martensite, which is related to the higher carbon content in solution. Jermolajev et $a l^{11}$ observed, through X-Ray diffraction analysis, that matensite tetragonality increases considerably in rehardened regions, so regions that have undergone superficial alterations in the microstructure during grinding process, which is in agreement with the observations made by SEM analysis of the samples, revealing a martensitic microstructure more acicular after grinding.

Figure 7 shows the values of Microhardness x Depth of the samples submitted to grinding in different conditions of cooling, and the sample without grinding. Microhardness values found are associated with the dissipation of heat and cooling rate of the specimens, because the temperature and cooling mode are determining factors in defining the obtained microstructure.

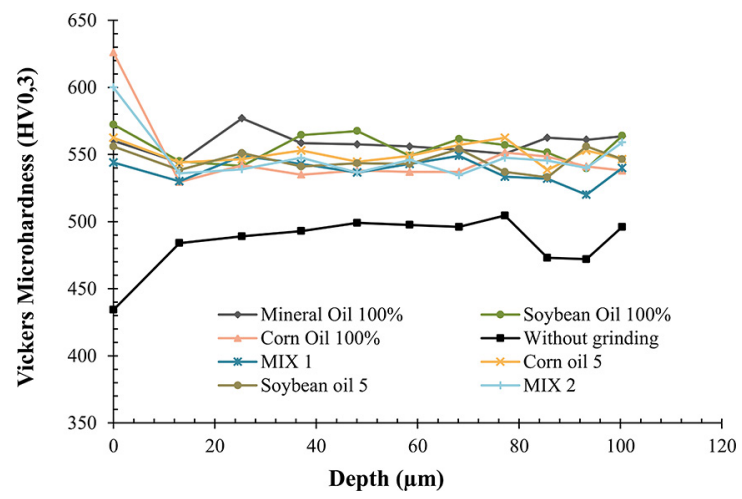

Figure 7. Microhardness profiles of the samples grinded in different conditions of cooling, and profile of the sample not grinded. 
By analyzing the graph it is observed that there are variations in hardness between the surface and sub-surface of all samples. Variations in the sub-surface are very small and do not present a standard of change with depth, thus the variations may be associated with the presence of a carbide at the site of indentation causing changes in values. The greatest variation between the surface and sub-surface was observed in the sample grinded with corn oil, possibly showing that cooling was not completely effective. The lowest microhardness values on the surface than in the sub-surface on grinded sample may be associated with inaccurate measurements due to its surface curvature. The microhardness values of the samples submitted to grinding were higher than the values of the sample not grinded, which is consistent with the microstructural analysis, which showed the presence of a martensitic microstructure more acicular in the grinded samples in comparison with the sample not grinded. Silva et $a l .{ }^{27}$ evaluated the microhardness of AISI 4340 submitted to grinding with conventional cutting fluid and found the same observations: the sample not grinded presented lower values of microhardness than the sample submitted to grinding process. The authors also verified that after grinding with MQL technique the samples presented loss of superficial hardness, which can be related to carbon diffusion in martensite associated to the inefficiency of cooling of lubricant ${ }^{27}$. As the samples grinded with the different formulations of cutting fluids did not presented loss of superficial hardness, we can infer that all the biodegradable formulations of cutting fluids were efficient during grinding of samples. A slight variation of microhardness in the other samples is also consistent with the micrographs, which showed martensite evenly distributed in the parts sub-surface.

\section{Conclusion}

The roughness measurements proved that grinding with the formulations of cutting fluid $100 \%$ Soybean Oil, Soybean Oil 5, Mix 1, Corn Oil 5 and Mix 2 were effective and have not been detrimental to the surface quality of parts, since the Ra roughness values found were close to those found in parts grinded with mineral oil.

The results of scanning electron microscopy and microhardness were consistent and demonstrated that there were not microstructural alterations different from the already expected alterations in grinding process regarding the use of cutting fluids. Microstructural analysis has shown that the use of biodegradable formulations of cutting fluids do not adversely alter the surface of the grinded parts.

In general, it is observed with the results that the soybean oil and Mix 1 formulation (containing mineral oil and soybean oil with additives) has high potential as a cutting fluid in grinding process, since the roughness, microstructure and microhardness evaluation were consistent with the results observed in the sample grinded with mineral oil. The positive results regarding the use of pure soybean oil in grinding process are promising, since it is a low cost, non-toxic and easily accessible possibility of cutting fluid.

\section{Acknowledgements}

The authors would like to express gratitude to CNPq for scholarship Research Productivity and FAPEMIG for assistance regarding the Scientific Initiation Scholarship Program.

\section{References}

1. Kuram E, Ozcelik B, Demirbas E, Sik E, Tansel IN. Evaluation of New Vegetable-Based Cutting Fluids on Thrust Force and Surface Roughness in Drilling of AISI 304 Using Taguchi Method. Materials and Manufacturing Processes. 2011;26(9):1136-1146.

2. Sadeghi MH, Hadad MJ, Tawakoli T, Vesali A, Emami M. An investigation on surface grinding of AISI 4140 hardened steel using minimum quantity lubrication-MQL technique. International Journal of Material Forming. 2010;3(4):241-245.

3. Hassanpour H, Sadeghi MH, Rasti A, Shajari S. Investigation of surface roughness, microhardness and white layer thickness in hard milling of AISI 4340 using minimum quantity lubrication. Journal of Cleaner Production. 2016;120:124-134.

4. Debnath S, Reddy MM, Yi QS. Environmental friendly cutting fluids and cooling techniques in machining: a review. Journal of Cleaner Production. 2014;83:33-47.

5. Sharma VS, Dogra M, Suri NM. Cooling techniques for improved productivity in turning. International Journal of Machine Tools and Manufacture. 2009;49(6):435-453.

6. Rabiei F, Rahimi AR, Hadad MJ, Ashrafijou M. Performance improvement of minimum quantity lucrication (MQL) technique in surface grinding by modeling and optimization. Journal of Cleaner Production. 2015;86:447-460.

7. Alves SM, Oliveira JFG. Development of new cutting fluid for grinding process adjusting mechanical performance and environmental impact. Journal of Materials Processing Technology. 2006;179(1-3):185-189.

8. Wang Y, Li C, Zhang Y, Li B, Yang M, Zhang X, et al. Experimental evaluation of the lubrication properties of the wheel/workpiece interface in MQL grinding with different nanofluids. Tribology International. 2016;99:198-210.

9. Malkin S. Grinding technology: theory and applications of machining with abrasives. Chichester: Ellis Horwood Limited; 1989.

10. Komanduri R, Hou ZB. A review of the experimental techniques for the measurement of heat and temperatures generated in some manufacturing processes and tribology. Tribology International. 2001;34(10):653-682.

11. Molaie MM, Akbari J, Movahhedy MR. Ultrasonic assisted grinding process with minimum quantity lubrication using oil-based nanofluids. Journal of Cleaner Production. 2016;129:212-222. 
12. Jermolajev S, Epp J, Heinzel C, Brinksmeier E. Material modifications caused by thermal and mechanical load during grinding. Procedia CIRP. 2016;45:43-46.

13. Ruzzi RS, Belentani RM, Mello HJ, Canarim RC, D'Addona DM, Diniz AE, et al. MQL with water in cylindrical plunge grinding of hardened steels using CBN wheels, with and without cleaning by compressed air. The International Journal of Advanced Manufacturing Technology. 2016;1-10.

14. Khan MMA, Dhar NR. Performance evaluation of minimum quantity lubrication by vegetable oil in terms of cutting force, cutting zone temperature, tool wear, job dimension and surface finish in turning AISI-1060 steel. Journal of Zhejiang UniversitySCIENCE A. 2006;7(11):1790-1799.

15. Kirsch B, Aurich JC. Influence of the macro-topography of grinding wheels on the cooling efficiency and the surface integrity. Procedia CIRP. 2014;13:8-12.

16. Zhou N, Peng RL, Pettersson R. Surface integrity of 2304 duplex stainless steel after different grinding operations. Journal of Materials Processing Technology. 2016;229:294-304.

17. Wang Y, Li C, Zhang Y, Yang M, Li B, Jia D, et al. Experimental evaluation of the lubrication properties of the wheel/workpiece interface in minimum quantity lubrication (MQL) grinding using different types of vegetable oils. Journal of Cleaner Production. 2016;127:487-499.

18. Shashidhara YM, Jayaram SR. Vegetable oils as a potential cutting fluid-An evolution. Tribology International. 2010;43(5-6):10731081.

19. Shyha I, Gariani S, Bhatti M. Investigation of cutting tools and working conditions effects when cutting Ti-6Al-4V using vegetable oil-based cutting fluids. Procedia Engineering. 2015;132:577-584.
20. Debnath S, Reddy MM, Yi QS. Influence of cutting fluid conditions and cutting parameters on surface roughness and tool wear in turning process using taguchi method. Measurement. 2016;78:111-119.

21. Lawal SA, Choudhury IA, Nukman Y. Application of vegetable oil-based metalworking fluids in machining ferrous metals-A review. International Journal of Machine Tools and Manufacture. 2012;52(1):1-12.

22. Reddy NSK, Rao PV. Experimental investigation to study the effect of solid lubricants on cutting forces and surface quality in end milling. International Journal of Machine Tools and Manufacture. 2006;46(2):189-198.

23. Lee WS, Su TT. Mechanical properties and microstructural features of AISI 4340 high-strength alloy steel under quenched and tempered conditions. Journal of Materials Processing Technology. 1999;87(1-3):198-206.

24. Zhirafar S, Rezaeian A, Pugh M. Effect of cryogenic treatment on the mechanical properties of 4340 steels. Journal of Materials Processing Technology. 2007;186(1-3):298-303.

25. Japanese Industrial Standards Comittee. JIS B 0601: Surface roughness. Tokio: Japanese Industrial Standards Committee; 2001.

26. ASTM International. ASTM E-384-99. Standard Test Method for Microindentation Hardness of Materials. West Conshohocken: ASTM International; 1999.

27. Silva LR, Corrêa ECS, Brandão JR, Ávila RF. Environmentally friendly manufacturing: Behavior analysis of minimum quantity of lubricant - MQL in grinding process. Journal of Cleaner Production. In Press. 